\title{
Catalytic peroxide fractionation processes for the green biorefinery of wood
} Kuznetsov B.N. ${ }^{{ }^{*}}$, Sudakova I.G. ${ }^{1}$, Garyntseva N.V. ${ }^{1}$, Kondrasenko A.A. ${ }^{1}$, Pestunov A.V. ${ }^{1}$, Djakovitch L. ${ }^{2}$, Pinel C. ${ }^{2}$

${ }^{1}$ Institute of Chemistry and Chemical Technology SB RAS, Federal Research Center

"Krasnoyarsk Science Center SB RAS”, Krasnoyarsk, Russia

2 IRCELYON, Lyon, France

*E-mail: bnk@icct.ru, ORCID0000-0001-6309-6482

\begin{abstract}
The kinetic study and optimization of pine wood peroxide fractionation in the medium acetic acid-water over $\mathrm{TiO}_{2}$ catalyst were firstly accomplished. Kinetic regularities and products composition of green processes of catalytic peroxide fractionation of softwood (pine, abies, larch) and hardwood (aspen, birch) over $1 \mathrm{wt}^{\%} \mathrm{TiO}_{2}$ catalyst in the acetic acid - water medium were compared at the temperature range $70-100^{\circ} \mathrm{C}$. For all type of wood the processes of peroxide delignification are described by the first order equations and their activation energies are varied at the range 76-94 kJ/mol. According to FTIR, XRD, SEM, NMR data the cellulosic products of peroxide delignification have a structure similar to microcrystalline cellulose regardless of the nature of wood. Soluble products are presented by organic acid and monosaccharides. The scheme of green biorefinery of pine wood based on extractive-catalytic fractionation of wood biomass on microcrystalline cellulose, hemicelluloses, aromatic and aliphatic acids, monosaccharides, turpentine and rosin was developed. Green and non-toxic reagents and solid catalyst are used in the developed scheme of biorefinery.
\end{abstract}

Keywords: softwood, hardwood, peroxide fractionation, catalyst $\mathrm{TiO}_{2}$, kinetics, optimization, green biorefinery.

\section{Introduction}

At wood felling, mechanical and chemical processing the huge number of wood waste is formed. Wood waste is the reliable source of renewable raw material for large-scale production of chemicals and biofuels. The production of demanded bioproducts from not food biomass will continue to grow taking into account the increasing cost of fossil fuels, deficiency of arable lands, the need of utilization of vegetable waste and reduction of $\mathrm{CO}_{2}$ emissions $[1,2]$.

Biomass of various tree species consists of cellulose, lignin, hemicelluloses, extracted substances and insignificant quantity of inorganic components [3]. Cellulose represents the linear polysaccharide constructed from chains of glucose, linked by $\beta-1,4$ bonds. Hemicelluloses are the branched polysaccharides, generally constructed from pentoses and hexoses connected by shorter, than in cellulose, chains. The lignin is aromatic nature polymer with branched structure. Lignin macromolecules consist of substituted phenylpropane units, connected with each other by ether and carbon - carbon bridges [3].

The specified types of vegetable polymers are structured by complex way in plant cells [3] and they are quite stable against chemical reagents and enzymes. For this reason, for lignocellulosic biomass processing the chemically aggressive and ecologically dangerous reagents, increased temperatures and pressures are applied. Due to this, the traditional technologies of wood chemical processing have a low productivity, they produce only limited range of products and influence negatively on an environment. 
In particular, industrial technologies of cellulose production use the ecologically hazardous sulfur and chlorine-containing delignification agents. Also they don't allow to provide the high-tech utilization of such components of wood, as lignin, hemicelluloses, extractive substances. Traditional technologies of wood hydrolysis, using the mineral acids as catalysts, already became outdated and don't meet the modern requirements for productivity, power consumption, resource-saving and ecological purity.

The new directions in the design of effective processes of biomass valorization to valuable chemicals, biofuels and functional polymers are connected with use of effective catalysts [4-6].

Promising ways in the development of innovative technologies of wood complex processing into valuable products are connected with a design of integrated catalytic processes which ensure the total utilization of all main components of biomass [7-9].

Most of them include, as a key stage, biomass fractionation on polysaccharides and lignin. Their further conversion makes possible to produce various chemicals and liquid biofuels.

In particular, integrated catalytic processing of pine wood based on wood catalytic oxidation with dioxygen allows to obtain vanillin from lignin and glucose from cellulose [10].

The processes of reductive catalytic fractionation make possible to separate lignocellulosic biomass into lignin-based soluble mono- and oligomers while retaining most of the carbohydrate in the pulp [11-13].

Single-stage processes of wood peroxide fractionation on cellulose and soluble lignin in "hydrogen peroxide-acetic acid-water" medium in the presence of $\mathrm{TiO}_{2}$ catalysts were developed [14]. The processes of catalytic peroxide fractionation were employed for the green biorefinery of birch wood to xylose, pure cellulose, glucose and liquid hydrocarbons [15], larch-wood to dihydroquercitin, arabinogalactan, microcrystalline cellulose and soluble low molecular weight lignin [16].

In this paper the kinetic study and optimization of pine wood peroxide fractionation in the medium acetic acid - water over the catalyst $1 \% \mathrm{TiO}_{2}$ (rutile) were firstly accomplished. The kinetics features and results of experimental and mathematical optimization of softwood (pine, abies, larch) and hardwood (aspen, birch) peroxide fractionation over catalyst $\mathrm{TiO}_{2}$ were compared.

The scheme of green biorefinery of pine wood based on fractionation of wood biomass on microcrystalline cellulose, organic acids, monosaccharides, turpentine and rosin was suggested.

\section{Experimental}

Air dry sawdust (fraction $0.5-2.0 \mathrm{~mm}$ ) of pine wood, abies wood, larch wood, aspen wood, birch wood were used in experiments. The contents of cellulose, lignin and hemicelluloses in wood were defined by analytical methods, common in wood chemistry [17]. The cellulose content in wood was defined by Kurschner method. The lignin content was determined by hydrolysis of the sample with $72 \mathrm{wt} \%$ of sulfuric acid at $20^{\circ} \mathrm{C}$ for $2.5 \mathrm{~h}$, followed by dilution of a solution with water and boiling for $1 \mathrm{~h}$. The hemicelluloses content was defined by McKein and Shoorly method using the hydrolysis by $2 \mathrm{wt} \% \mathrm{HCl}$ at $100{ }^{\circ} \mathrm{C}$ during 3 h.

The composition of wood samples is given in Table 1 . 
Table 1 Composition of wood samples

\begin{tabular}{llcc}
\hline \multirow{2}{*}{ Wood } & & Composition, wt $\%$ & Lignin \\
\cline { 2 - 4 } & Cellulose & Hemicelluloses & 28.0 \\
\hline Pine wood & 47.6 & 16.5 & 26.8 \\
Abies wood & 45. & 17.7 & 28.2 \\
Larch wood & 41.3 & 26.6 & 21.9 \\
Aspen wood & 46.3 & 24.5 & 21.8 \\
Birch wood & 46.5 & 27.2 & 2 \\
\hline
\end{tabular}

For the isolation of resinous substances, the pine wood was extracted with petroleum ether in Soxhlet apparatus at temperature of $90{ }^{\circ} \mathrm{C}$ for $6-12$ hours. Thereafter, the petroleum ether was removed by distillation at 90 ${ }^{\circ} \mathrm{C}$ and a mixture of raw rosin and turpentine was obtained as a solid residue. Separation of turpentine and rosin was carried out by distillation of this residue under vacuum.

The process of wood sawdust fractionation was carried out in a $250-\mathrm{mL}$ glass reactor, equipped with a mechanical stirrer, reflux condenser, and thermometer.

The suspension of commercial $\mathrm{TiO}_{2}$ (GOST 9808-84) with the average particle size of $10 \mu \mathrm{m}$, phase composition of $92 \%$ rutile and $8 \%$ anatase, and BET specific area $3 \mathrm{~m}^{2} / \mathrm{g}$ was used as a catalyst.

Wood sawdust (10 g) was charged into the reactor, and then a solution containing a mixture of acetic acid, hydrogen peroxide, deionized water and catalyst was added. To prepare the reaction mixture, acetic acid (chemically pure grade, GOST 61-75), hydrogen peroxide (GOST 177-88), and deionized water (GOST 6709-72) were used. All reactants were purchased in ZAO Khimreaktivsnab (Russia). The reaction mixture was stirred intensively $(700 \mathrm{rpm})$ at selected temperature $\left(70-100^{\circ} \mathrm{C}\right)$ for $1-4 \mathrm{~h}$. The reaction temperature was kept using a Termeks thermostat (Tomsk, Russia). The composition of the reaction solution varied within the following limits: hydrogen peroxide 4-6 wt \%, acetic acid 15-30wt \%, liquid/wood ratio (LWR) 10-20. The content of the catalyst $\mathrm{TiO}_{2}$ was $1 \%$ relative to the weight of the reaction solution. At the end of the process, the solid precipitate was separated by vacuum filtration on a Buchner funnel, washed with deionized water, and dried at $105^{\circ} \mathrm{C}$ to a constant weight.

The yield of the cellulosic product was determined by the weight method and calculated by the equation

$$
\mathrm{Y}=\frac{\mathrm{m}}{\mathrm{m}_{0}} \times 100
$$

where $\mathrm{Y}$ is the yield of the cellulosic product (in wt \%), $\mathrm{m}$ is the weight of the absolutely dry cellulose product (in $\mathrm{g}$ ), $\mathrm{m}_{0}$ is the weight of the absolutely dry wood (in $\mathrm{g}$ ).

The residual lignin content in cellulosic product was used to evaluate the delignification activity of $\mathrm{TiO}_{2}$ catalyst.

The contents of cellulose, residual lignin and hemicelluloses in solid products were determined using the standard chemical methods [17].

Infrared spectroscopy analysis (FTIR) was carried out in transmission mode. Samples of cellulose (4 mg for each) were prepared in pellet with matrix KBr. The spectra were recorded with Bruker Tensor 27 in the range of $4000-400 \mathrm{~cm}^{-1}$. Spectral data were processed by the program OPUS/YR (version 2.2).

X-ray diffraction (XRD) analysis was carried out using PANalyticalX'Pert Pro (PANalytical, Netherlands) spectrometer with $\mathrm{CuK} \alpha$ radiation $(\lambda=0.54 \mathrm{~nm})$. The analysis was performed in the angle 
range of $2 \theta=5^{\circ}-70^{\circ}$ with a step of $0.1^{\circ}$ on the powder sample in a $2.5-\mathrm{cm}$ diameter cuvette. The crystallinity index of the cellulose was calculated from the ratio of crystalline peak intensity to the total intensity after substracting the background signal [18].

Solid state ${ }^{13} \mathrm{C}$ CP-MAS NMR spectra were recorded with the use of Bruker Avance III spectrometer, operating at $150.9 \mathrm{MHz} 13 \mathrm{C}$ resonance frequency. Samples were packed in $3.2 \mathrm{~mm}$ rotors and spun at $7.5 \mathrm{kHz}$. All spectra were aquired at $25{ }^{\circ} \mathrm{C}$. Acquisition parameters were set as follows: acquisition time $0.33 \mathrm{~ms}$, crosspolarization contact time $3 \mathrm{~ms}$, 4096 accumulated scans with repetition interval $5 \mathrm{~s}$. Chemical shifts were referenced relative to adamantane as external standard (methylene at $\delta^{13} \mathrm{C}$ $=29.5 \mathrm{ppm}$ ). Acquired free induction decays were multiplied with exponential window function with $25 \mathrm{~Hz}$ line broadening before Fourier transformation.

Scanning electron microscopy (SEM) of the samples was performed on a JSM 7001 F (JEOL, Japan) microscope with acceleration potentional $15 \mathrm{kV}$. Samples were coated on carbon support.

\section{Results and discussion}

$\underline{\text { Selection of catalyst for peroxide fractionation of wood biomass }}$

Catalytic peroxide fractionation of wood makes possible to obtain microcrystalline cellulose (MCC) and low molecular weight products from lignin and hemicelluloses. MCC is used in pharmaceutical, cosmetic, food industries and in other areas [19].

Traditional methods of MCC obtaining from wood are multistage and dangerous for the environment due to the use of toxic sulfur- and chlorine-containing delignifying agents and mineral acids [19]. New ecology friendly methods of cellulose obtaining include the processes of oxidative catalytic delignification of lignocellulosic biomass with the use such "green" reagents, as oxygen and hydrogen peroxide [20].

Earlier, we suggested to obtain microcrystalline cellulose with the use of one-stage process of aspen wood peroxide fractionation in acetic acid-water medium in the presence of sulfuric acid catalyst [21]. However, the $\mathrm{H}_{2} \mathrm{SO}_{4}$ catalyst not only accelerates the lignin depolymerization reactions, but also promotes the hydrolysis of the amorphous part of the cellulose, which leads to a decrease in the yield of cellulosic product. Besides, the sulfuric acid is a toxic and corrosive catalyst.

Mo-containing and $\mathrm{TiO}_{2}$ catalysts were active in peroxide fractionation of aspen-wood at temperatures $90-100{ }^{\circ} \mathrm{C}$. But molybdenum-containing catalysts are expensive. The successful replacement of the dangerous $\mathrm{H}_{2} \mathrm{SO}_{4}$ catalyst on non-toxic and non-corrosive $\mathrm{TiO}_{2}$ catalyst in the process of peroxide fractionation of aspen-wood was demonstrated in [22]. Besides, the similar kinetic regularities of aspenwood peroxide fractionation in the presence of $2 \% \mathrm{H}_{2} \mathrm{SO}_{4}$ and $1 \% \mathrm{TiO}_{2}$ catalysts point on the same mechanism of lignin depolymerization [22].

Catalytic properties of $\mathrm{TiO}_{2}$ samples in anatase and rutile modifications were compared in the process of aspen wood peroxide delignification at $100{ }^{\circ} \mathrm{C}$ [23]. At the same process conditions the use of titanium dioxide catalyst in rutile modification with low surface area $\left(2 \mathrm{~m}^{2} / \mathrm{g}\right)$ gives the cellulosic product with lower content of residual lignin and higher cellulose content, as compared to $\mathrm{TiO}_{2}$ in anatase modification with higher surface area $\left(89-11 \mathrm{~m}^{2} / \mathrm{g}\right)$. The reduced catalytic activity of $\mathrm{TiO}_{2}$ anatase can be explained by the following reasons [23]. Probably, the smaller size of pores in anatase samples (12.4-13.1 $\mathrm{nm})$ as compared to rutile sample $(17.9 \mathrm{~nm})$ reduces their catalytic activity in wood delignification owing to strengthening of diffusion limitations inside pores. Besides that, a higher concentration of hydrogen groups 
on the surface of anatase modification of $\mathrm{TiO}_{2}$, as compared to its rutile modification can prevent the formation from $\mathrm{H}_{2} \mathrm{O}_{2}$ the hydroxyl and peroxide radicals, active in oxidative depolymerization of lignin.

The commercial $\mathrm{TiO}_{2}\left(92 \%\right.$ rutile and $8 \%$ anatase) with BET surface area $3 \mathrm{~m}^{2} / \mathrm{g}$ was selected for the study of kinetic features of softwood (pine, abies, larch) and hardwood (aspen, birch) peroxide fractionation in the acetic acid - water medium at temperature range $70-100{ }^{\circ} \mathrm{C}$.

Kinetic study and optimization of pine wood peroxide fractionation over $\mathrm{TiO}_{2}{ }_{2}$ catalyst

To optimize the process of pine wood peroxide fractionation in the presence of $\mathrm{TiO}_{2}$ catalyst the influence of temperature, concentrations of hydrogen peroxide and acetic acid, liquid/wood ratio, time on the dynamics of lignin removal from wood was studied.

The increase of temperature from $70{ }^{\circ} \mathrm{C}$ to $100{ }^{\circ} \mathrm{C}$ reduces significantly the content of residual lignin and of hemicelluloses in the cellulosic product (Table 2). But at the same time the yield of cellulosic product is decreased. The oxidative destruction of lignin, hemicelluloses and the amorphous part of cellulose in wood is accelerated when the delignification temperature increased from 70 to $100^{\circ} \mathrm{C}$.

Table 2 Impact of delignification temperature and time on the yield and composition of cellulosic products obtained from pine wood $\left(\mathrm{CH}_{3} \mathrm{COOH} 25 \mathrm{wt} \%, \mathrm{H}_{2} \mathrm{O}_{2} 6 \mathrm{wt} \%\right.$, LWR 15, $\left.1 \mathrm{wt} \% \mathrm{TiO}_{2}\right)$

\begin{tabular}{cccccc}
\hline $\begin{array}{c}\text { Temperature, } \\
{ }^{\circ} \mathrm{C}\end{array}$ & Time, h & $\begin{array}{c}\text { Yield of cellulosic product, } \\
\text { wt } \%^{*}\end{array}$ & \multicolumn{2}{c}{ Composition of product, wt $\%^{* *}$} \\
\cline { 4 - 6 } & & 73.6 & 64.7 & 7.1 & 27.8 \\
70 & 2 & 72.3 & 65.8 & 6.5 & 27.3 \\
70 & 3 & 70.2 & 67.8 & 5.9 & 25.9 \\
70 & 4 & 65.8 & 72.3 & 5.6 & 21.7 \\
80 & 1 & 69.6 & 68.4 & 6.7 & 24.5 \\
80 & 2 & 69.9 & 68.1 & 7.3 & 24.2 \\
80 & 3 & 67.4 & 70.6 & 7.2 & 21.8 \\
80 & 4 & 66.5 & 71.6 & 5.7 & 22.3 \\
90 & 1 & 70.1 & 67.9 & 7.1 & 24.6 \\
90 & 2 & 65.7 & 72.4 & 6.4 & 20.8 \\
90 & 3 & 60.3 & 78.9 & 5.6 & 15.1 \\
90 & 4 & 54.9 & 86.7 & 4.9 & 8.0 \\
100 & 1 & 62.8 & 75.8 & 5.1 & 18.7 \\
100 & 2 & 53.3 & 89.2 & 6.0 & 4.4 \\
100 & 3 & 45.8 & 92.3 & 3.7 & 3.6 \\
100 & 4 & 44.3 & 94.7 & 4.0 & 0.9 \\
\hline
\end{tabular}

* on abs.dry wood, $* *$ on abs.dry product

Delignification of pine wood at $70{ }^{\circ} \mathrm{C}$ during $4 \mathrm{~h}$ gives $65.8 \mathrm{wt} \%$ yield of cellulosic product containing 72.3 $\mathrm{wt} \%$ of cellulose and $21.7 \mathrm{wt} \%$ of lignin. When raising the temperature to $100{ }^{\circ} \mathrm{C}$, the yield of cellulosic product decreased to $44.3 \mathrm{wt} \%$. The maximum content of cellulose in the product (94.7 wt $\%$ ) was detected after 4-hour delignification of pine wood at $100{ }^{\circ} \mathrm{C}$. Under such conditions, the residual lignin was actually absent in this sample and hemicelluloses amount was $4.0 \mathrm{wt} \%$. 
Figure 2 demonstrates the influence of $\mathrm{H}_{2} \mathrm{O}_{2}$ concentration on the yield and composition of cellulosic product obtained at $100{ }^{\circ} \mathrm{C}$. In the presence of $4.0 \mathrm{wt} \%$ of $\mathrm{H}_{2} \mathrm{O}_{2}$ the yield of cellulosic product is $64.3 \mathrm{wt} \%$, but it has a rather high content of residual lignin $\left(12.3 \mathrm{wt} \%\right.$ ). When the concentration of $\mathrm{H}_{2} \mathrm{O}_{2}$ increases to $6.0 \mathrm{wt} \%$, the content of residual lignin reduces to $1.0 \mathrm{wt} \%$, but the yield of cellulosic product decreased simultaneously to 44.5 $\mathrm{wt} \%$.

At the high concentration of $\mathrm{H}_{2} \mathrm{O}_{2}$, the oxidation of wood carbohydrates occurs along with the oxidation of lignin. According to the data obtained, the optimum concentration of $\mathrm{H}_{2} \mathrm{O}_{2}$, corresponding to a high yield of cellulosic product (near $44 \mathrm{wt} \%$ on a.d.w.) and to a low lignin content in cellulosic product $(0.9$ wt $\%$ on a.d.p.) is 6 wt $\%$ (Fig. 1).

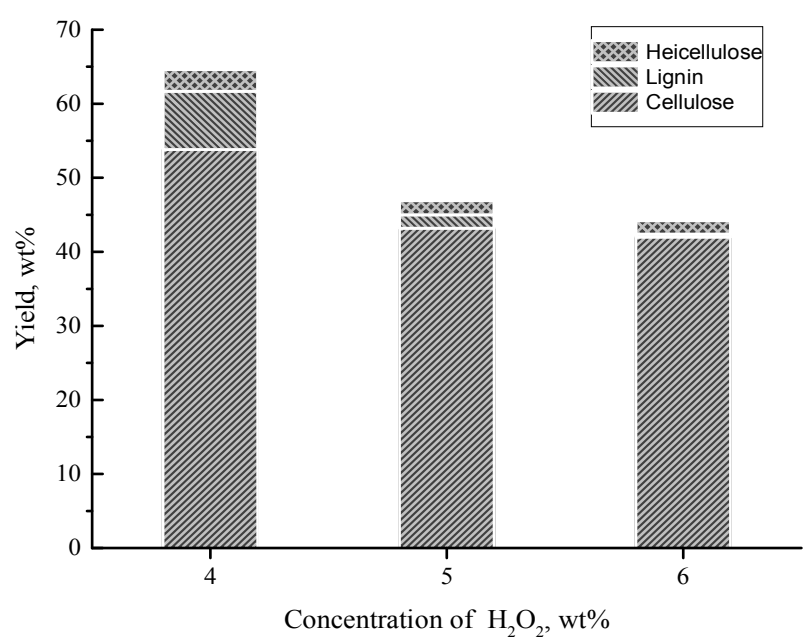

Fig.1 Impact of concentration of $\mathrm{H}_{2} \mathrm{O}_{2}$ on the yield and composition of cellulosic products obtained from pine wood $\left(\mathrm{CH}_{3} \mathrm{COOH} 25 \mathrm{wt} \%\right.$, LWR $15,100^{\circ} \mathrm{C}$, time $\left.4 \mathrm{~h}, 1 \mathrm{wt} \% \mathrm{TiO}_{2}\right)$

The rise of acetic acid concentration in reaction mixture decreases the yield of cellulosic product along with the reduction of residual lignin content (Fig.2). While acetic acid concentration was increased from 15 to $30 \mathrm{wt} \%$, the yield of cellulosic product reduced from 48.1 to $44.3 \mathrm{wt} \%$. Simultaneously, the content of cellulose in cellulosic product was increased from 91.0 up to $94.8 \mathrm{wt} \%$ and that of residual lignin - from 4.5 to $0.9 \mathrm{wt} \%$. According to obtained data the optimum concentration of acetic acid is nearly $25 \mathrm{wt} \%$. This concentration allows to reach the acceptable yield of cellulosic product (44.5 wt \%) with high amount of cellulose $(94.7 \mathrm{wt} \%)$ and low content of residual lignin $(1.0 \mathrm{wt} \%)$. 


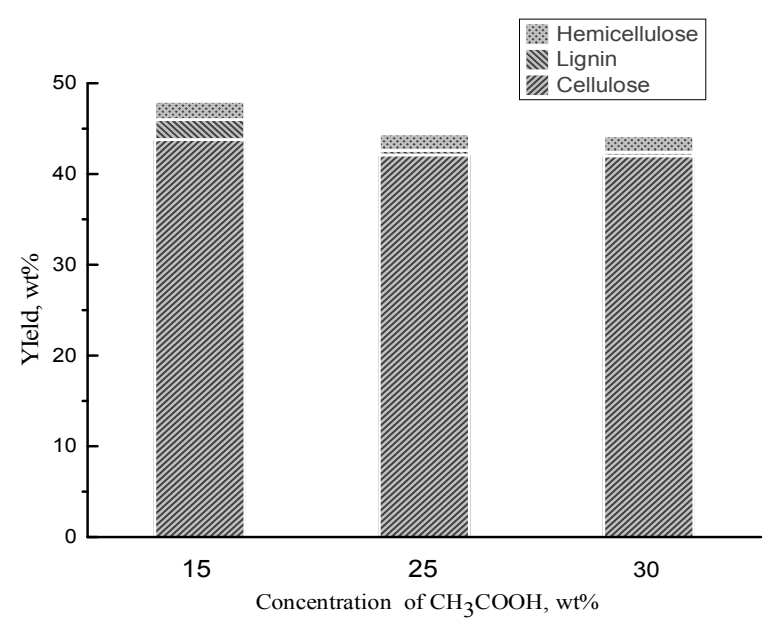

Fig.2 Impact of concentration of $\mathrm{CH}_{3} \mathrm{COOH}$ on the yield and composition of cellulosic products obtained from pine wood $\left(\mathrm{H}_{2} \mathrm{O}_{2} 6 \mathrm{wt} \%\right.$, LWR $15,100{ }^{\circ} \mathrm{C}$, time $\left.4 \mathrm{~h}, 1 \mathrm{wt} \% \mathrm{TiO}_{2}\right)$

The value of the liquid/wood ratio (LWR) allows controlling both the yield and composition of cellulosic products (Fig.3). The cellulosic products obtained at liquid/wood ratio of 15-20 have low content of residual lignin (1-0.5 wt \%). The reduction of LWR to 10 increases both the amount of cellulosic product to $48.0 \mathrm{wt} \%$ and of residual lignin content to $4.9 \mathrm{wt} \%$. A possible reason for this is a hindered diffusion of lignin oxidation products from wood to solution at low LWR. As a result, the intermediates of lignin oxidative fragmentation are recondensed to so-called "pseudo lignin" [24]. According to obtained data the optimal LWR value for peroxide delignification of pine wood at $100{ }^{\circ} \mathrm{C}$ is equal to 15 .

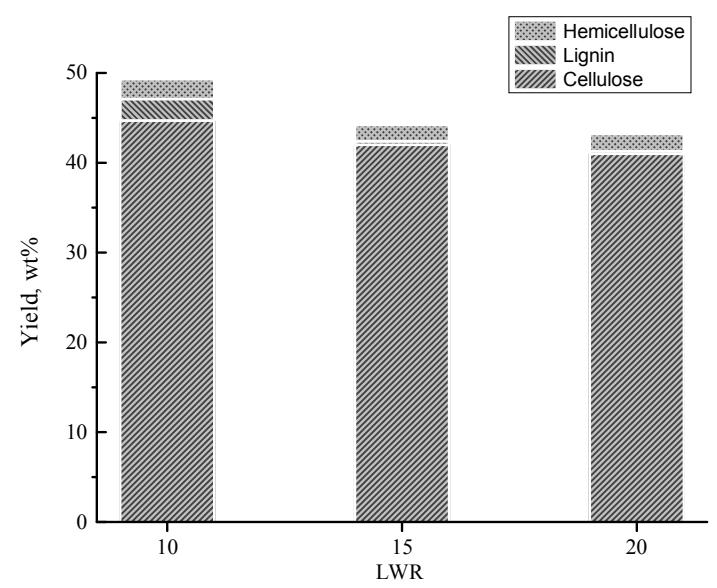

Fig.3 Impact of LWR value on the yield and composition of cellulosic products obtained from pine wood $\left(\mathrm{H}_{2} \mathrm{O}_{2} 6\right.$ wt $\%, \mathrm{CH}_{3} \mathrm{COOH} 25 \mathrm{wt} \%, 100{ }^{\circ} \mathrm{C}$, time $4 \mathrm{~h}, 1 \mathrm{wt} \% \mathrm{TiO}_{2}$ )

The kinetic study of pine wood peroxide catalytic fractionation in the temperature range $70-100{ }^{\circ} \mathrm{C}$ was accomplished. The variation of lignin concentration in the cellulosic product was used for calculating the rate constants of delignification process. It was found that the process of lignin isolation from pine wood is described by the first order equation (Fig.4). 


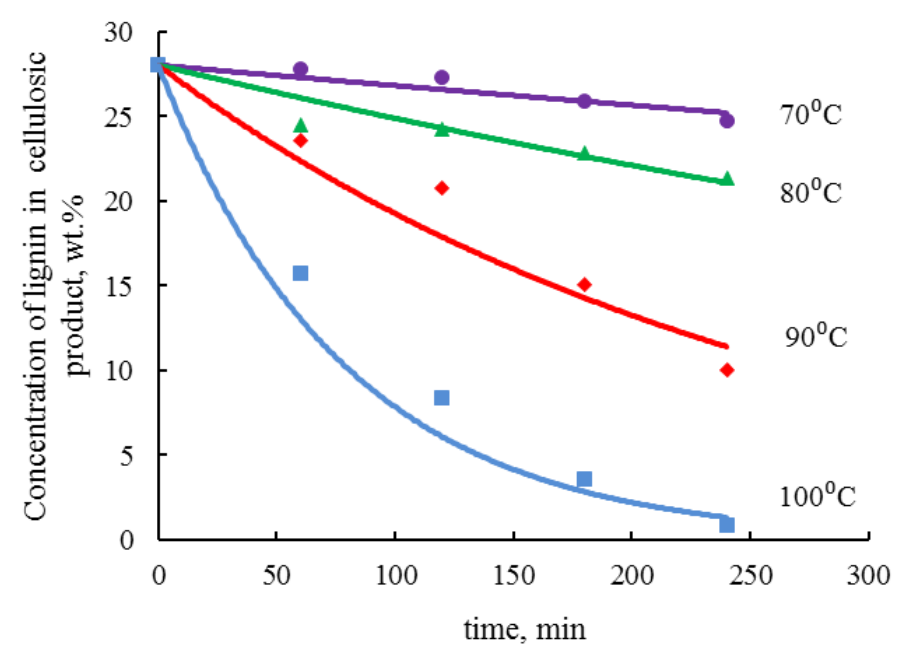

Fig.4 Dynamic of lignin isolation in the process of pine wood peroxide fractionation $\left(\mathrm{H}_{2} \mathrm{O}_{2} 6 \mathrm{wt} \%, \mathrm{CH}_{3} \mathrm{COOH} 25\right.$ wt $\%$, LWR $15,1 \mathrm{wt} \% \mathrm{TiO}_{2}$ )

The rate constants of pine wood peroxide delignification increase from $0.07 \cdot 10^{-4} \mathrm{~s}^{-1}$, to $2.1710^{-4} \mathrm{~s}^{-1}$ with a rise in temperature from $70^{\circ} \mathrm{C}$ to $100^{\circ} \mathrm{C}$.

The activation energy of pine wood peroxide delignification process was determined using temperature dependence of the rate constants in Arrhenius coordinates. The rather high value of activation energy $(94 \mathrm{KJ} / \mathrm{mol})$ points on the minor contribution of external diffusion limitations at the used conditions of pine wood peroxide delignification over $\mathrm{TiO}_{2}$ catalyst.

The numerical optimization of the process of pine wood peroxide delignification over $\mathrm{TiO}_{2}$ catalyst was carried out with the use of Statgraphics application software, according to earlier described procedure [14]. The main purpose of the optimization was to find conditions for the most complete removal of lignin from wood, while maintaining a sufficiently high yield of cellulosic product.

As independent parameters, the following factors have been selected: $\mathrm{X}_{1}-\mathrm{H}_{2} \mathrm{O}_{2}$ concentration in reaction solution, wt $\% ; \mathrm{X}_{2}-$ liquid / wood ratio. The other process parameters were fixed: temperature $100{ }^{\circ} \mathrm{C}$, concentration of acetic acid $25 \mathrm{wt} \% ; \mathrm{TiO}_{2} 1 \mathrm{wt} \%$, time $4 \mathrm{~h}$.

The following output parameters for optimization were selected: $\mathrm{Y}_{1}$ - the cellulosic product yield, $\mathrm{wt} \%$; $\mathrm{Y}_{2}$ - the cellulose content in the product, $\mathrm{wt} \% ; \mathrm{Y}_{3}$ - lignin content in the product, $\mathrm{wt} \%$.

Optimization was performed with the use of generalized parameter of optimization $\left(\mathrm{W}_{\mathrm{a}}\right)$ which was calculated as in [23].

Analysis of variances showed that the effect of both factors $X_{1}$ and $X_{2}$ on the generalized parameter of optimizations statistically significant (P-Value less than 0.05 and the confidence levels above 95\%).

As a result of mathematical processing the following regression equation was obtained:

$$
\mathrm{Wa}=3.49+0.68 \cdot \mathrm{X}_{1}+0.32 \cdot \mathrm{X}_{2}-0.03 \cdot \mathrm{X}_{1} \cdot \mathrm{X}_{2}-0.04 \cdot \mathrm{X}_{2}^{2}
$$

Response surface of the generalized parameter of the optimization is presented on Fig.5. 


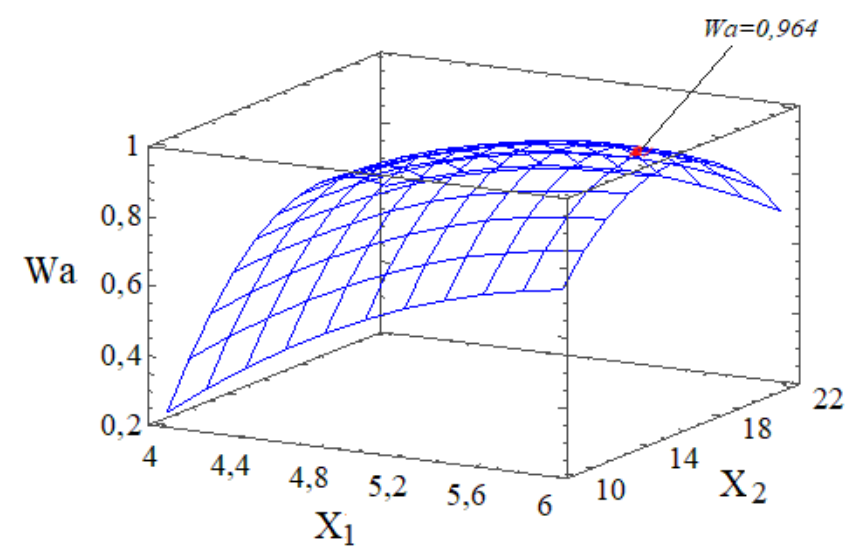

Fig. 5 Response surface of the generalized parameter $\left(\mathrm{W}_{\mathrm{a}}\right)$ of the optimization of pine wood peroxide delignification over $\mathrm{TiO}_{2}$ catalyst: $\mathrm{X}_{1}$ - initial concentration of $\mathrm{H}_{2} \mathrm{O}_{2}, \mathrm{X}_{2}$ - liquid /wood ratio

It was found, that the generalized parameter of the optimization is set to 0.873 . This corresponds to the following optimal parameters of pine wood delignification process: temperature $100{ }^{\circ} \mathrm{C}$, concentrations of $\mathrm{H}_{2} \mathrm{O}_{2} 6$ $\mathrm{wt} \%$ and of $\mathrm{CH}_{3} \mathrm{COOH} 25 \mathrm{wt} \%$, LWR 15, duration $4 \mathrm{~h}$.

The cellulosic product obtained by peroxide fractionation of pine wood at optimal conditions with an yield $44.5 \mathrm{wt} \%$ has the following composition (wt \%): cellulose 94.7 , hemicelluloses 4.0 , lignin 1.0.

Comparison of kinetic features of softwood and hardwood peroxide fractionation over $\mathrm{TiO}_{2}$ catalyst

Results of the present study along with the previously obtained data [14-16] show that the processes of peroxide delignification of softwood (pine, abies, larch) and hardwood (aspen, birch) over $\mathrm{TiO}_{2}$ catalyst are described by the first order equations.

These processes have the similar values of activation energies $(76-94 \mathrm{~kJ} / \mathrm{mol})$. But the peroxide delignification of hardwood proceeds with a higher rate as compared to softwood at the temperature range 70-90 ${ }^{\circ} \mathrm{C}$ (Table 3).

Table 3 Rate constants of the processes of softwood and hardwood peroxide fractionation over $1 \mathrm{wt} \% \mathrm{TiO}_{2}$ catalyst $\left(\mathrm{H}_{2} \mathrm{O}_{2} 6 \mathrm{wt} \%, \mathrm{CH}_{3} \mathrm{COOH} 25 \mathrm{wt} \%\right.$, LWR $\left.15,4 \mathrm{~h}\right)$

\begin{tabular}{ccc}
\hline Temperature, ${ }^{\circ} \mathrm{C}$ & $\begin{array}{c}\text { Rate constants } \\
\mathrm{k} \cdot 10^{-4}, \mathrm{~s}^{-1}\end{array}$ & Activation energy, $\mathrm{kJ} / \mathrm{mol}$ \\
\hline 70 & Pine wood & \\
80 & 0.07 & \\
90 & 0.20 & \\
100 & 0.62 & 86 \\
\hline 70 & 2.17 & \\
\hline 80 & Abies wood & \\
\hline 100 & 0.08 & 0.19 \\
\hline
\end{tabular}




\begin{tabular}{ccc}
\hline & Larch wood & \\
\hline 70 & 0.10 & 88 \\
80 & 0.28 & \\
90 & 0.68 & \\
100 & 2.84 & 76 \\
\hline 70 & Aspen wood & \\
80 & 0.18 & \\
90 & 0.56 & \\
100 & 1.19 & \\
\hline 70 & 1.56 & \\
\hline 80 & Birch wood & \\
\hline 100 & 0.14 & \\
\hline
\end{tabular}

Composition and structure of cellulose products obtained from different types of wood

The structure of solid cellulosic products obtained by peroxide delignification of hardwood and softwood over $\mathrm{TiO}_{2}$ catalyst at optimized process conditions (Table 4) was studied by FTIR, XRD and ${ }^{13} \mathrm{C}$ CP-MAS NMR methods.

Table 4 Optimized conditions of wood peroxide fractionation processes, the yield and composition of cellulosic products $\left(100^{\circ} \mathrm{C}, 4 \mathrm{~h}\right)$

\begin{tabular}{|c|c|c|c|c|c|}
\hline \multirow{2}{*}{$\begin{array}{l}\text { Wood } \\
\text { nature }\end{array}$} & \multirow{2}{*}{ Optimized conditions } & \multirow{2}{*}{$\begin{array}{l}\text { Yield of cellulosic } \\
\text { product, } \mathrm{wt}^{*} \%\end{array}$} & \multicolumn{3}{|c|}{ Composition of product, wt $\%^{* *}$} \\
\hline & & & Lignin & Cellulose & Hemicelluloses \\
\hline $\begin{array}{l}\text { Pine } \\
\text { wood }\end{array}$ & $\begin{array}{c}\mathrm{H}_{2} \mathrm{O}_{2} 6 \%, \\
\mathrm{CH}_{3} \mathrm{COOH} 25 \%, \\
\text { LWR } 15\end{array}$ & 44.5 & 1.0 & 94.7 & 4.0 \\
\hline $\begin{array}{l}\text { Abies } \\
\text { wood }\end{array}$ & $\begin{array}{c}\mathrm{H}_{2} \mathrm{O}_{2} 6 \%, \mathrm{CH}_{3} \mathrm{COOH} \\
30 \%, \\
\text { LWR } 15\end{array}$ & 52.6 & 2.3 & 91.6 & 5,7 \\
\hline $\begin{array}{l}\text { Larchwo } \\
\text { od }\end{array}$ & $\begin{array}{c}\mathrm{H}_{2} \mathrm{O}_{2} 6 \%, \\
\mathrm{CH}_{3} \mathrm{COOH} 30 \%, \\
\text { LWR } 15\end{array}$ & 44.2 & 0.6 & 93.8 & 4.5 \\
\hline $\begin{array}{l}\text { Aspen } \\
\text { wood }\end{array}$ & $\begin{array}{c}\mathrm{H}_{2} \mathrm{O}_{2} 5 \%, \mathrm{CH}_{3} \mathrm{COOH} \\
25 \%, \\
\text { LWR } 15\end{array}$ & 50.2 & 0.7 & 92.7 & 5.5 \\
\hline $\begin{array}{l}\text { Birch } \\
\text { wood }\end{array}$ & $\begin{array}{c}\mathrm{H}_{2} \mathrm{O}_{2} 5 \%, \mathrm{CH}_{3} \mathrm{COOH} \\
25 \%, \\
\text { LWR } 15\end{array}$ & 48.2 & 0.5 & 93.7 & 5.5 \\
\hline
\end{tabular}

* on abs. dry wood;** on abs. dry cellulosic product 
The FTIR spectra of cellulosic products from wood and the sample of commercial MCC Vivapur are very similar (Fig.6). All samples have an absorption bands attributed to microcrystalline cellulose $[25,26]$. The absence in the spectrum of cellulosic product from wood the peaks in the range 1509-1609 $\mathrm{cm}^{-1}$, which would correspond to $\mathrm{C}=\mathrm{C}$ aromatic skeletal vibrations, indicates the absence of residual lignin in the cellulosic product.

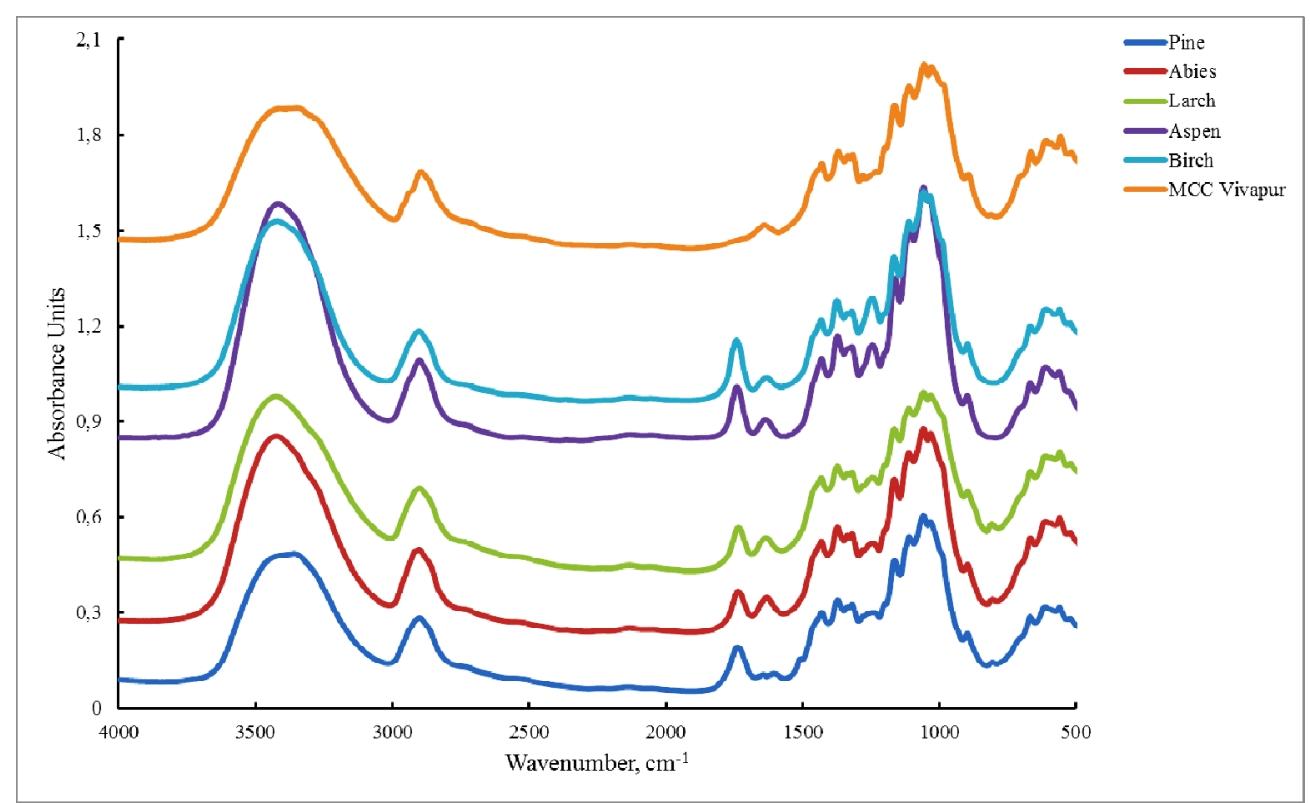

Fig.6 FTIR spectra of cellulosic products obtained by peroxide delignification of different types of wood and of commercial MCC Vivapur

According to X-ray diffraction data (Fig.7) the samples of cellulose obtained by peroxide delignification of different types of wood have the structure, similar to the commercial MCC. Diffractograms of all cellulosic samples contain two intensive peaks with maximum $2 \theta$ equal $22.6^{\circ}$ (plane 002 ) and $16.2^{\circ}$ (plane 110). A well crystallized and homogeneous on the lattice parameters of MCC gives narrow and high diffraction peaks. XRD data (Fig.7) suggest that the crystal structure of MCC samples obtained from all types of wood is the monoclinic cellulose I [27].

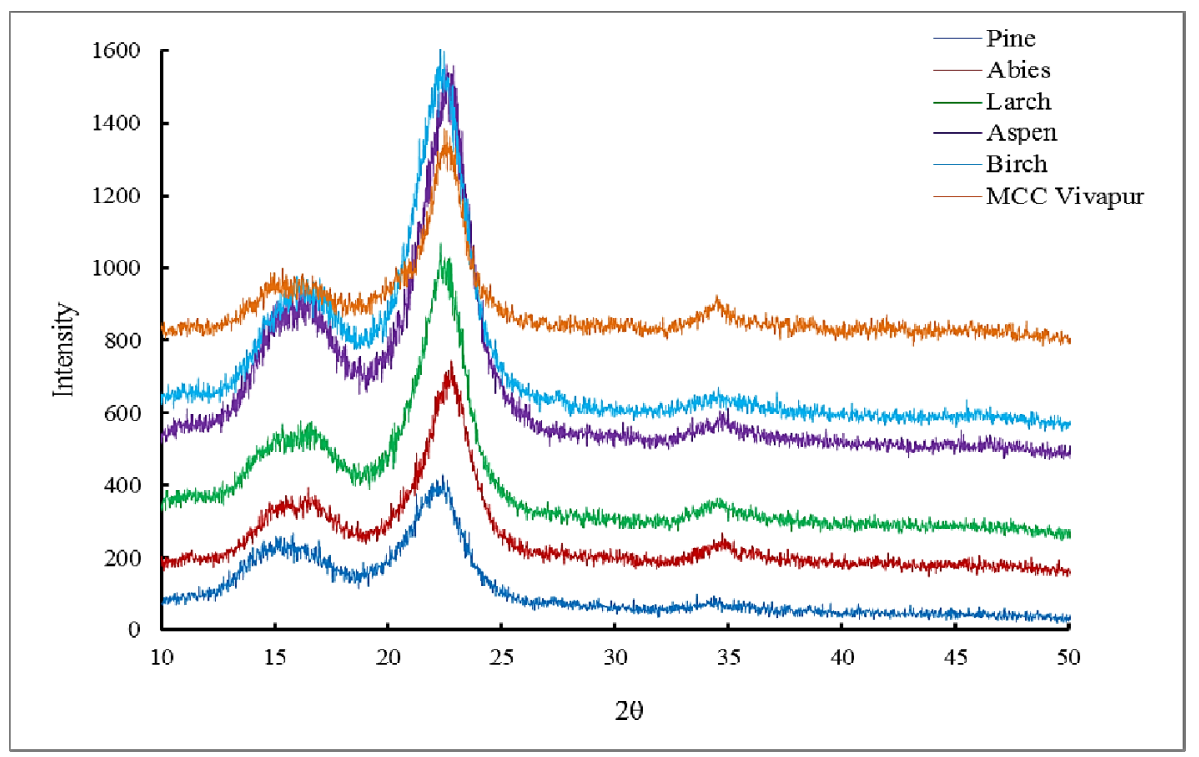

Fig.7 Diffractograms of cellulosic products obtained by peroxide delignification of different types of wood and of commercial MCC Vivapur 
According to the XRD data, the crystallinity index of MCC samples obtained from wood are close to the crystallinity index of industrial MCC Vivapur (Table 5) [28].

Table 5 Structural characteristics of cellulose samples

\begin{tabular}{ccc}
\hline Sample & Crystallinity index & $\begin{array}{c}\text { Average size of crystalline } \\
\text { grains }(\mathrm{nm})\end{array}$ \\
\hline Cellulose from pine wood & 0.69 & 3.3 \\
Cellulose from abies wood & 0.73 & 3.2 \\
Cellulose from larch wood & 0.70 & 3.4 \\
Cellulose from aspen wood & 0.68 & 3.1 \\
Cellulose from birch wood & 0.71 & 3.6 \\
Commercial MCC Vivapur & 0.75 & 3.5 \\
\hline
\end{tabular}

In order to compare the structure of cellulosic products obtained from different types of wood and MCC Vivapur, the ${ }^{13} \mathrm{C}$ CP-MAS NMR solid state analysis was performed. The resonance lines of cellulosic products from different wood and MCC Vivapur were almost similar (Fig. 8). All spectra have resonance lines which indicate the presence of crystalline and amorphous forms of cellulose. Initial chemical shifts of peaks were set and assigned according to data from Wikberg and Maunu [29]. Peaks have been assigned based on the literature data [29,30] and they are displayed in the Table 6.

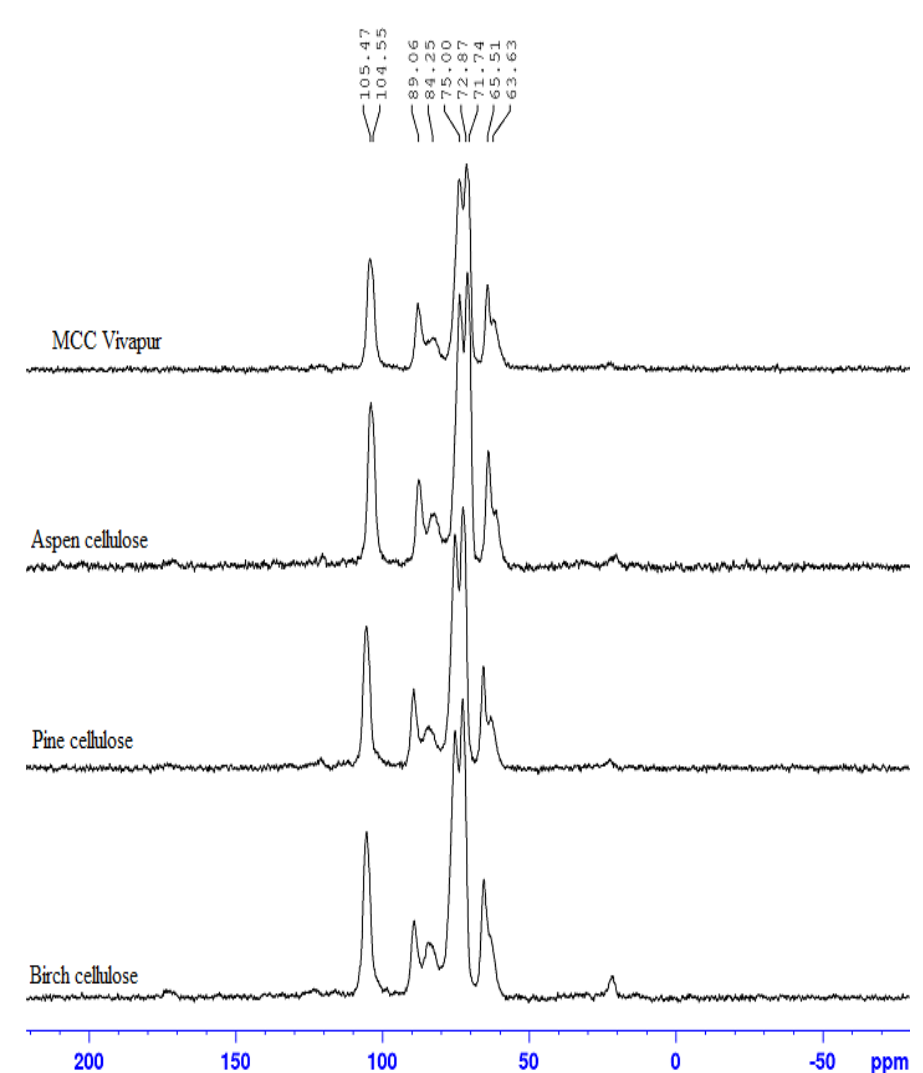

Fig. $8{ }^{13} \mathrm{C}$ CP-MAS NMR spectra of cellulosic products
Table 6 Signal assignments for ${ }^{13} \mathrm{C}$ CP-MAS NMR spectra of cellulosic products obtained by peroxide delignification of different types of wood and of commercial MCC Vivapur

\begin{tabular}{cc}
\hline $\begin{array}{c}\text { Chemical shift } \\
(\mathrm{ppm})\end{array}$ & Assignment \\
\hline 173 & C-1 of cellulose \\
105 & C-4 of crystalline cellulose \\
89 & C-4 of amorphous cellulose \\
84 & C-2/C-3/C-5 \\
$72-75$ & of cellulose \\
65 & C-6 of crystalline cellulose \\
62 & C-6 of amorphous cellulose \\
21 &
\end{tabular}


According to SEM data the cellulosic products, obtained by catalytic peroxide fractionation of different types of wood, consist of microfibrils of different lengths. Some microfibrils combine into aggregates with a length of 140 to $270 \mu \mathrm{m}$ (Fig. 9). The morphology of the particles is similar to the morphology of the commercial MCC Vivapur, in which the length of the aggregates of the microfibrils is $100-160 \mu \mathrm{m}$.

Pine

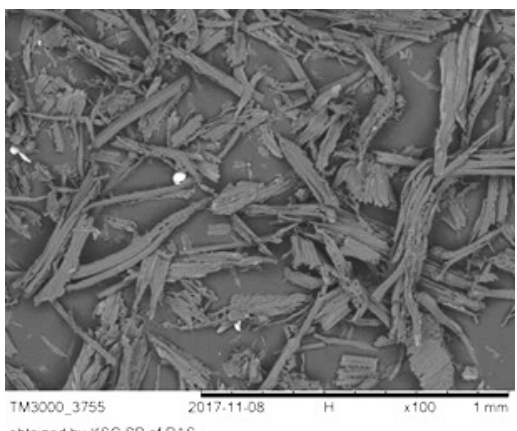

obtained by KSC SB of RAS

Aspen

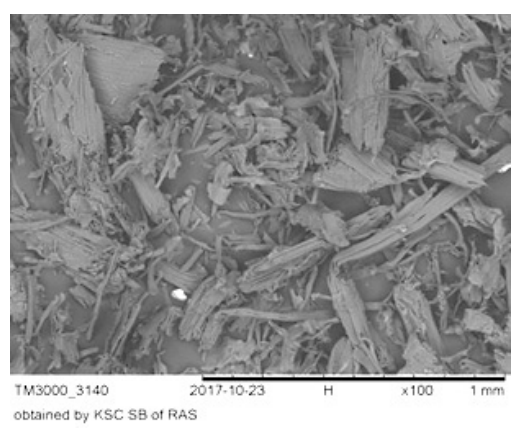

Abies
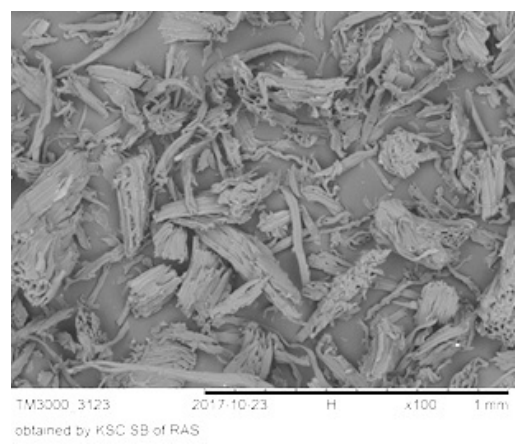

Birch

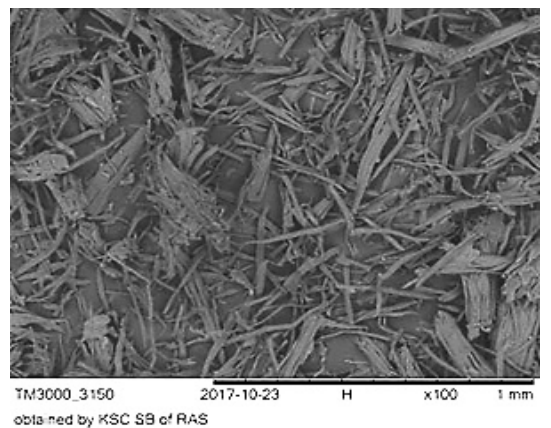

Larch

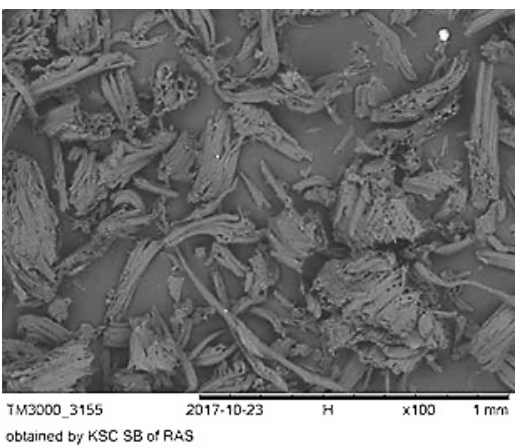

MCC Vivapur

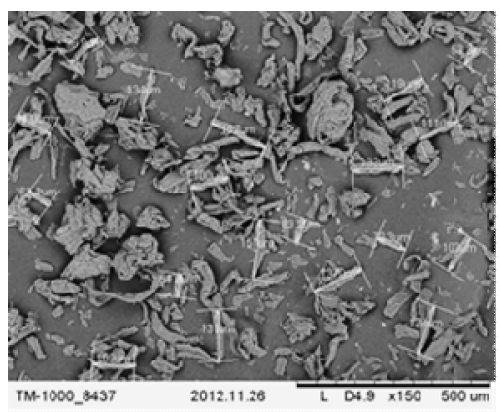

Fig. 9 SEM images of cellulosic products obtained by peroxide delignification of different types of wood and of commercial MCC Vivapur

$\underline{\text { Suggested scheme of green biorefinery of pine wood }}$

The pine is fast-growing and one of the most common tree species. The pine wood is widely used in woodworking and construction industries. This creates a huge amount of wood waste that must be disposed. High content of resinous substances in pine wood complicates its processing into quality cellulose using traditional delignification technologies.

Promising way in the development of innovative technologies of wood complex processing to valuable products are connected with a design of integrated processes which ensure the total utilization of all main components of biomass [31-33].

In a previous paper [15], we suggested to use the catalytic peroxide fractionation of hard wood biomass to polysaccharides and lignin as a key process of biorefinery of low-grade wood.

Based on this approach, the scheme of green biorefinery of pine wood biomass is proposed which integrates the optimized processes of biomass fractionation on MCC, organic acids, monosaccharides, turpentine and rosin. (Fig. 10). 


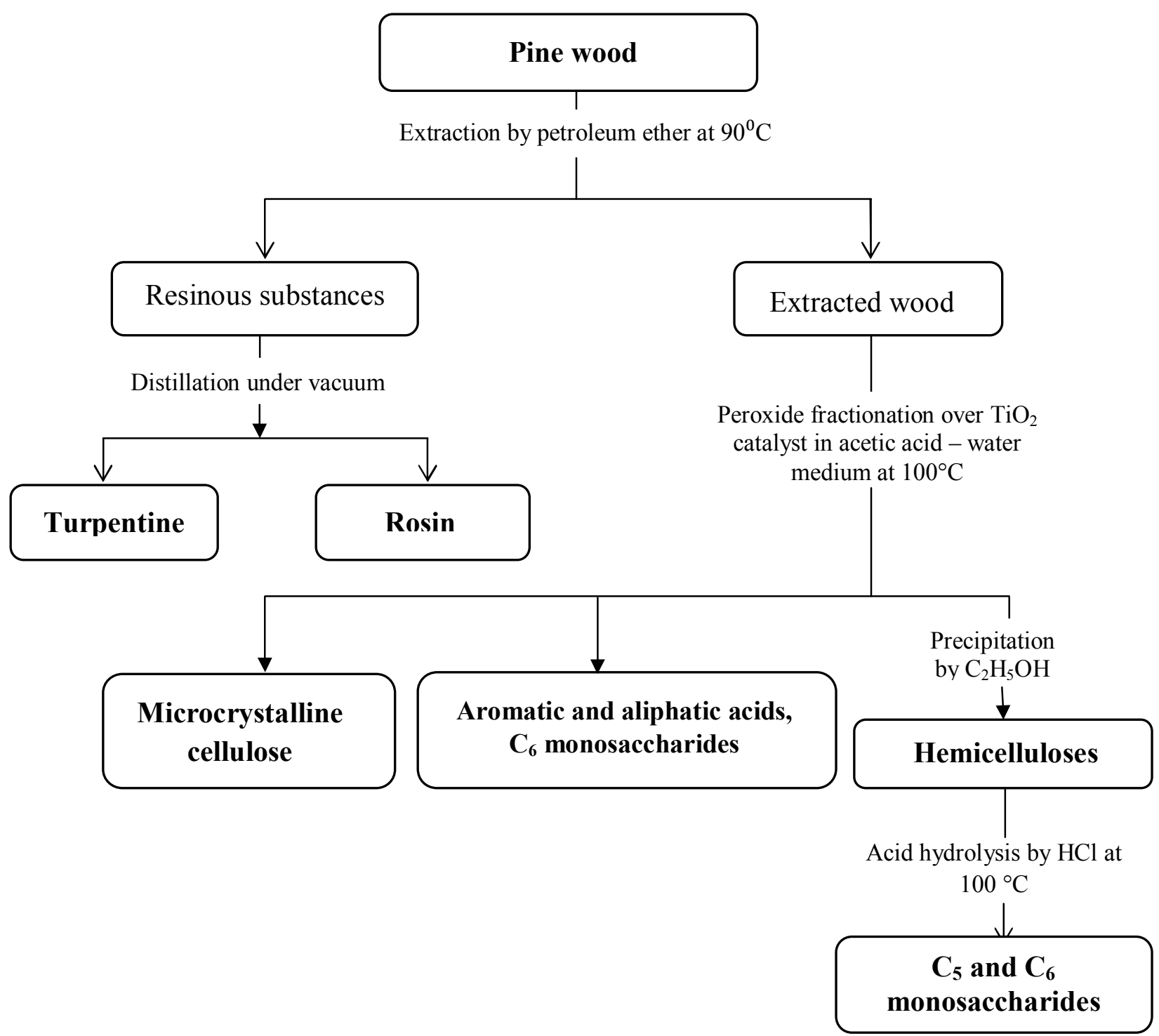

Fig.10 Suggested scheme of green biorefinery of pine wood

Resinous substances of pine wood are presented such valuable products, as: turpentine and rosin. They are used in their natural form, as well as raw materials for production of various valuable chemicals [34,35].

We used the extraction of pine wood with petroleum ether at $90{ }^{\circ} \mathrm{C}$ as a first stage of pine wood biorefinery. The impact of the extraction time on the yield of resinous substances was studied. As follows from Figure 11, the yield of resinous substances increases from 2.1 to $5.8 \mathrm{wt} \%$ with the rise of extraction time from 6 to 12 hours.

The distillation of resinous substances at $90^{\circ} \mathrm{C}$ under vacuum was used to separate turpentine and rosin. 


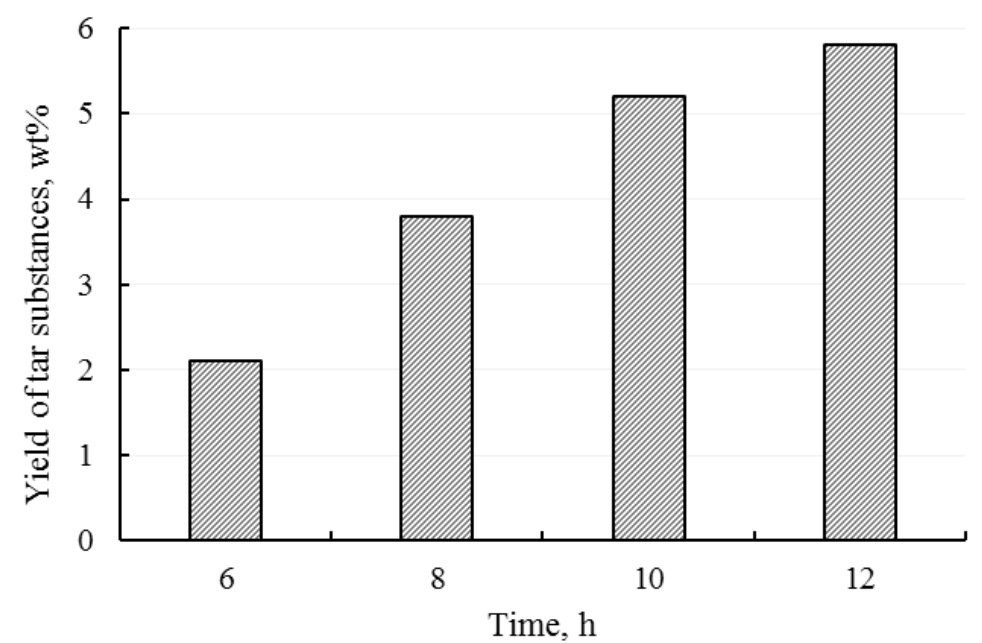

Fig. 11 Yield of resinous substances isolated from pine wood by extraction of petroleum ether at $90{ }^{\circ} \mathrm{C}$

The yields of products (wt $\%$ on abs. dry wood) reach to 4.06 for rosin and to 1.74 for turpentine.

The yield of microcrystalline cellulose obtained at optimal conditions of pine wood peroxide fractionation $\left(100{ }^{\circ} \mathrm{C}, \mathrm{H}_{2} \mathrm{O}_{2} 6 \mathrm{wt} \%, \mathrm{CH}_{3} \mathrm{COOH} 25 \mathrm{wt} \%\right.$, LWR 15 , time $\left.4 \mathrm{~h}\right)$ is $44.5 \mathrm{wt} \%$.

Soluble products of pine wood peroxide fractionation are presented by hemicelluloses and low molecular weight products which formed by depolymerization of lignin and amorphous cellulose.

The yield of hemicelluloses which were deposited by ethanol is $5.4 \mathrm{wt} \%$ (33 wt\% from initial content in wood). The hydrolysis of hemicelluloses by $2 \% \mathrm{HCl}$ at $100^{\circ} \mathrm{C}$ gives a mixture of monosaccharides (Table 7). In their composition prevails mannose and glucose $(87.55 \%)$ and xylose (10.65\%).

According to GC-MS data, the soluble low molecular weight products mainly represented by organic acids and $\mathrm{C}_{6}-$ monosaccharides (Table 8). The content of aromatic acids (3-hydroxy-4-methoxybenzoic, 4hydroxybenzoic, 4-hydroxy-3,5-methoxybenzoic) in soluble products reaches to $48.6 \%$ and that of mannose and glucose - to $21.9 \%$.

Thus in the framework of the developed scheme of pine wood biorefinery it is possible to obtain microcrystalline cellulose, aromatic acids from lignin, monosaccharides from amorphous cellulose, turpentine and rosin from resinous substances.

Such "green" and non-toxic reagents, as water, hydrogen peroxide, acetic acid, petroleum ether, ethanol and non-corrosive solid catalyst are used in the developed scheme of pine wood biorefinery.

Table 7 Products of hydrolysis of pine wood hemicelluloses by $2 \% \mathrm{HCl}$ at $100{ }^{\circ} \mathrm{C}$ (data of $\mathrm{GC}$ analysis)

\begin{tabular}{ccc}
\hline \multirow{2}{*}{ Substance } & \multicolumn{2}{c}{ Content } \\
\cline { 2 - 3 } & $\mathrm{g} / \mathrm{ml}$ & rel.\% \\
\hline Arabinose & 0.084 & 0.10 \\
Xylose & 8.50 & 10.65 \\
Galactose & 1.36 & 1.70 \\
Mannose & 46.28 & 58.04 \\
Glucose & 23.54 & 29.51 \\
\hline
\end{tabular}


Table 8 Soluble products obtained at peroxide fractionation of pine wood under optimal conditions (data of GC-MS analysis)

\begin{tabular}{lc}
\hline Substance & Content, rel.\% \\
\hline Adipic acid & 13.8 \\
Ethyl ether of succinic acid & 0.6 \\
Fumaric acid & 2.5 \\
4-hydroxybenzoic acid & 15.9 \\
3-hydroxy-4-methoxybenzoic acid & 22.6 \\
Azelaic acid & 5.2 \\
Malic acid & 2.3 \\
4-hydroxy-3,5-methoxybenzoic acid & 10.1 \\
Ethylvanilate & 2.0 \\
2,4-hexanedioic acid & 3.1 \\
Mannose & 11.9 \\
Glucose & 10.0 \\
\hline
\end{tabular}

\section{Conclusion}

The results of the kinetic study and optimization of the process of pine wood peroxide fractionation at 70$100{ }^{\circ} \mathrm{C}$ over $\mathrm{TiO}_{2}$ (rutile) catalyst in the acetic acid - water medium are firstly described.

Kinetic regularities of the processes of softwood (pine, abies, larch) and hardwood (aspen, birch) catalytic peroxide fractionation at these conditions were compared.

Softwood contains more lignin than hardwood; therefore the higher concentration of hydrogen peroxide is needed for deep delignification of pine, abies and larch wood in comparison with aspen and birch wood.

At the temperature range $70-90{ }^{\circ} \mathrm{C}$ the peroxide delignification of hardwood proceeds with a higher rate as compared to softwood since the softwood lignins have a less reactive closed-packed structure, constructed mainly from guaiacyl-type units.

Cellulosic products, obtained by peroxide delignification of hardwood and softwood have the structure of microcrystalline cellulose. Soluble products consist of aromatic and aliphatic acids, mannose and glucose.

Scheme of green biorefinery of pine wood was developed which integrates the optimized processes of biomass fractionation on microcrystalline cellulose, hemicelluloses, aromatic and aliphatic acids, monosaccharides, rosin and turpentine.

\section{Acknowledgements}

This work is a part of GDRI "Biomass” between France and Russia. 


\section{References}

1. Introduction to Chemicals from Biomass (2008). Wiley Series in Renewable Resources. John Wiley \& Sons, Ltd Chichester

2. Nelson V (2011) Introduction to Renewable Energy. Energy and the environment. CRS Press, London, New York

3. Fengel D, Wegener, G. (1984) Wood Chemistry, Ultrastracture, Reactions. Walter de Gruter, Berlin

4. Gallezot P (2007) Catalytic routes from renewables to fine chemicals. Catalysis Today 121 (1):76-91

5. Serrano-Ruiz JC, Dumesic JA (2011) Catalytic routes for the conversion of biomass into liquid hydrocarbon transportation fuels. Energy \& Environmental Science 4 (1):83-99

6. Besson M, Gallezot P, Pinel C (2014) Conversion of Biomass into Chemicals over Metal Catalysts. Chemical Reviews 114 (3):1827-1870.

7. Zakzeski J, Bruijnincx PCA, Jongerius AL, Weckhuysen BM (2010) The Catalytic Valorization of Lignin for the Production of Renewable Chemicals. Chemical Reviews 110 (6):3552-3599

8. Cherubini F, Jungmeier G, Wellisch M, Willke T, Skiadas I, Ree RV, Jong Ed (2009) Toward a common classification approach for biorefinery systems. Biofuels, Bioproducts and Biorefining 3 (5):534-546

9. de Long E, Hidson, A., Walsh, P. (2013) Task 42. Biorefinery In: Report IEA Bioenergy

10. Tarabanko VE, Kaygorodov KL, Skiba EA, Tarabanko N, Chelbina YV, Baybakova OV, Kuznetsov BN, Djakovitch L (2017) Processing Pine Wood into Vanillin and Glucose by Sequential Catalytic Oxidation and Enzymatic Hydrolysis. Journal of Wood Chemistry and Technology 37 (1):43-51

11. Van den Bosch S, Schutyser W, Vanholme R, Driessen T, Koelewijn SF, Renders T, De Meester B, Huijgen WJJ, Dehaen W, Courtin CM, Lagrain B, Boerjan W, Sels BF (2015) Reductive lignocellulose fractionation into soluble lignin-derived phenolic monomers and dimers and processable carbohydrate pulps. Energy \& Environmental Science 8 (6):1748-1763

12. Galkin MV, Samec, J.S.M (2016) Lignin Valorization through Catalytic Lignocellulose Fractionation: A Fundamental Platform for the Future Biorefinery ChemSusChem 9:1544-1558

13. Anderson EM, Katahira R, Reed M, Resch MG, Karp EM, Beckham GT, Román-Leshkov Y (2016) Reductive Catalytic Fractionation of Corn Stover Lignin. ACS Sustainable Chemistry \& Engineering 4 (12):6940-6950

14. Kuznetsov BN, Sudakova IG, Garyntseva NV, Djakovitch L, Pinel C (2017) Kinetic studies and optimization of abies wood fractionation by hydrogen peroxide under mild conditions with $\mathrm{TiO} 2$ catalyst. Reaction Kinetics, Mechanisms and Catalysis 120 (1):81-94

15. Kuznetsov BN, Chesnokov NV, Yatsenkova OV, Sharypov VI, Garyntseva NV, Ivanchenko NM, Yakovlev VA (2017) Green catalytic valorization of hardwood biomass into valuable chemicals with the use of solid catalysts. Wood Science and Technology 51 (5):1189-1208

16. Kuznetsov BN, Sudakova IG, Garyntseva NV, Levdansky VA, Ivanchenko NM, Pestunov AV, Djakovitch L, Pinel C (2018) Green biorefinery of larch wood biomass to obtain the bioactive compounds, functional polymers and nanoporous materials. Wood Science and Technology 52 (5):1377-1394

17. Analytical Methods in Wood Chemistry, Pulping and Papermaking (1999). Springer Series in Wood Science. Springer-Verlag Berlin Heidelberg

18. Park S, Baker JO, Himmel ME, Parilla PA, Johnson DK (2010) Cellulose crystallinity index: measurement techniques and their impact on interpreting cellulase performance. Biotechnology for Biofuels 3 (1):10

19. Trache D, Hussin MH, Hui Chuin CT, Sabar S, Fazita MRN, Taiwo OFA, Hassan TM, Haafiz MKM (2016) Microcrystalline cellulose: Isolation, characterization and bio-composites application-A review. International Journal of Biological Macromolecules 93:789-804 
20. Suchy M, Argyropoulos, D. (2002) Catalysis and activation of oxygen and peroxide delignification of chemical pulps: a review. Tappi $1(2): 1-18$

21. Kuznetsov BN, Sudakova IG, Garyntseva NV, Djakovitch L, Pinel C (2013) Kinetic study of aspen-wood sawdust delignification by $\mathrm{H} 2 \mathrm{O} 2$ with sulfuric acid catalyst under mild conditions. Reaction Kinetics, Mechanisms and Catalysis $110(2): 271-280$

22. Kuznetsov BN, Chesnokov NV, Garyntseva NV, Sudakova IG, Pestunov AV, D’yakovich L, Pinel' K (2018) Kinetic Study and Optimization of Catalytic Peroxide Delignification of Aspen Wood. Kinetics and Catalysis 59 (1):48-57

23. Kuznetsov BN, Chesnokov NV, Sudakova IG, Garyntseva NV, Kuznetsova SA, Malyar YN, Yakovlev VA, Djakovitch L (2018) Green catalytic processing of native and organosolv lignins. Catalysis Today 309:18-30

24. Hu F, Jung S, Ragauskas A (2012) Pseudo-lignin formation and its impact on enzymatic hydrolysis. Bioresource Technology 117:7-12

25. Adel AM, Abd El-Wahab ZH, Ibrahim AA, Al-Shemy MT (2011) Characterization of microcrystalline cellulose prepared from lignocellulosic materials. Part II: Physicochemical properties. Carbohydrate Polymers 83 (2):676-687 26. Fan M, Dai, D., Huang, B. Fourier transform infrared spectroscopy for natural fibres. In: Salih S (ed) International Conference on Innovative Technologies (IN-TECH 2012), Rejeka, Croatia, 2012. pp 45-68

27. Nishiyama Y, Langan P, Chanzy H (2002) Crystal Structure and Hydrogen-Bonding System in Cellulose I $\beta$ from Synchrotron X-ray and Neutron Fiber Diffraction. Journal of the American Chemical Society 124 (31):90749082

28. Vasiliu-Oprea C, Nicoleanu J (1993) Micronized (and Microcrystalline) Celluloses. Obtainment and Fields of Application. Polymer-Plastics Technology and Engineering 32 (3):181-214

29. Wikberg H, Liisa Maunu S (2004) Characterisation of thermally modified hard- and softwoods by 13C CPMAS NMR. Carbohydrate Polymers 58 (4):461-466

30. Zuckerstatter G, Schild, G., Wollboldt, P., Roeder, T., Weber, HK, Sixta, H. (2009) The elucidation of cellulose supramolecular structure by 13C CP-MAS NMR. Lenzing Ber 87:38-46

31. Liu D, Chen EYX (2014) Integrated Catalytic Process for Biomass Conversion and Upgrading to C12 Furoin and Alkane Fuel. ACS Catalysis 4 (5):1302-1310

32. Schutyser W, Renders T, Van den Bosch S, Koelewijn SF, Beckham GT, Sels BF (2018) Chemicals from lignin: an interplay of lignocellulose fractionation, depolymerisation, and upgrading. Chemical Society Reviews 47 (3):852-908

33. Alonso DM, Hakim SH, Zhou S, Won W, Hosseinaei O, Tao J, Garcia-Negron V, Motagamwala AH, Mellmer MA, Huang K, Houtman CJ, Labbé N, Harper DP, Maravelias CT, Runge T, Dumesic JA (2017) Increasing the revenue from lignocellulosic biomass: Maximizing feedstock utilization. Science Advances 3 (5)

34. Silvestre AJ, Gandini, A., (2008) Monomers, Polymers and Composites From Renewable Resources. Elsevier, 35. B. Mercier JP, M. Prost (2009) The essential oil of turpentine and its major volatile fraction ( $\alpha$ - and $\beta$-pinenes): A review International Journal of Occupational Medicine and Environmental Health 22 (4):331-342 